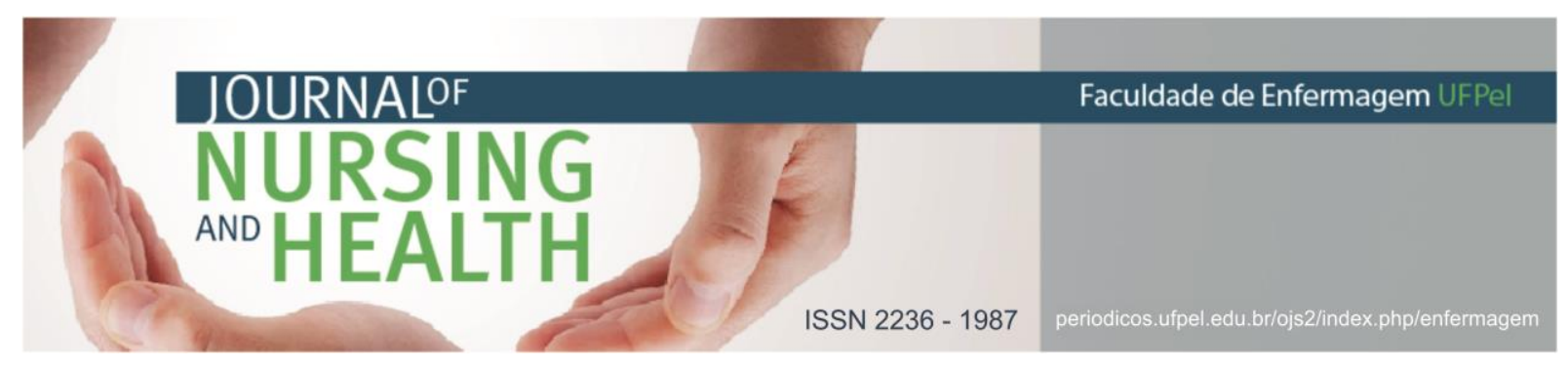

ENTREVISTA NARRATIVA

\title{
Valorizando as experiências pessoais, dialogando com as vozes e possibilitando o convívio: relatos de Ron Coleman
}

\section{Valuing personal experiences, talking with the voices and making possible to get along with the voices: reports of Ron Coleman}

\section{Valorando las experiencias personales, dialogando con las voces y posibilitando la convivencia: relatos de Ron Coleman}

Brum, Aline Neutzling ${ }^{1}$; Jardim, Vanda Maria da Rosa ${ }^{2}$; Pavani, Fabiane Machado ${ }^{3}$ Wetzel, Christine ${ }^{4}$

Como citar este artigo: Brum AN, Jardim VMR, Pavani FM, Wetzel C. Valorizando as experiências pessoais, dialogando com as vozes e possibilitando o convívio: relatos de Ron Coleman. J. nurs. health. 2018;8(n.esp.):e188429

Palavras-chave: Saúde mental; Ouvir vozes; Vozes.

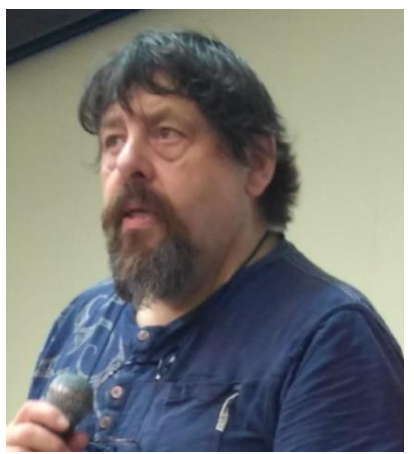

\section{APRESENTAÇÃO}

A narrativa aqui apresentada considera fatos pessoais e profissionais relacionados a vida de Ron Coleman. Nos estudos de saúde mental com foco no tema de ouvidores de vozes, Coleman se destaca por inúmeras publicações e por sua experiência como participante e moderador de grupos de ouvidores de vozes, além de suas contribuições à rede internacional de ouvidores de vozes.

Ron Coleman é pioneiro no trabalho desenvolvido pela rede internacional de ouvidores de vozes, esteve presente no primeiro grupo de ouvidores de vozes do Reino Unido, Manchester, 1991 e veio ao Brasil especialmente para participar do Congresso.

Em significativa oportunidade, Ron Coleman concedeu uma entrevista às pesquisadoras do Grupo onde relatou sobre sua relação e trajetória junto ao Movimento de Ouvidores de Vozes e sobre a importância do congresso que acontecia naquele momento.

\footnotetext{
1 Bióloga. Pós-doutora em Ciências da Saúde. Universidade Federal do Rio Grande (FURG). E-mail: neutzling@live.dehttps://orcid.org/0000-0002-9686-9602

2 Enfermeira. Doutora em Enfermagem. Universidade Federal de Pelotas (UFPEL). E-mail: vandamrjardim@gmail.com http://orcid.org/0000-0001-8320-4321

3 Enfermeira. Universidade Federal do Rio Grande do Sul (UFRGS). E-mail: fabianepavani04@gmail.com http://orcid.org/0000-0002-3858-8036.

4 Enfermeira. Doutora em Enfermagem Psiquiátrica. Universidade Federal do Rio Grande do Sul (UFRGS). E-mail: cwetzel@ibest.com.br http://orcid.org/0000-0002-3858-8036.
} 


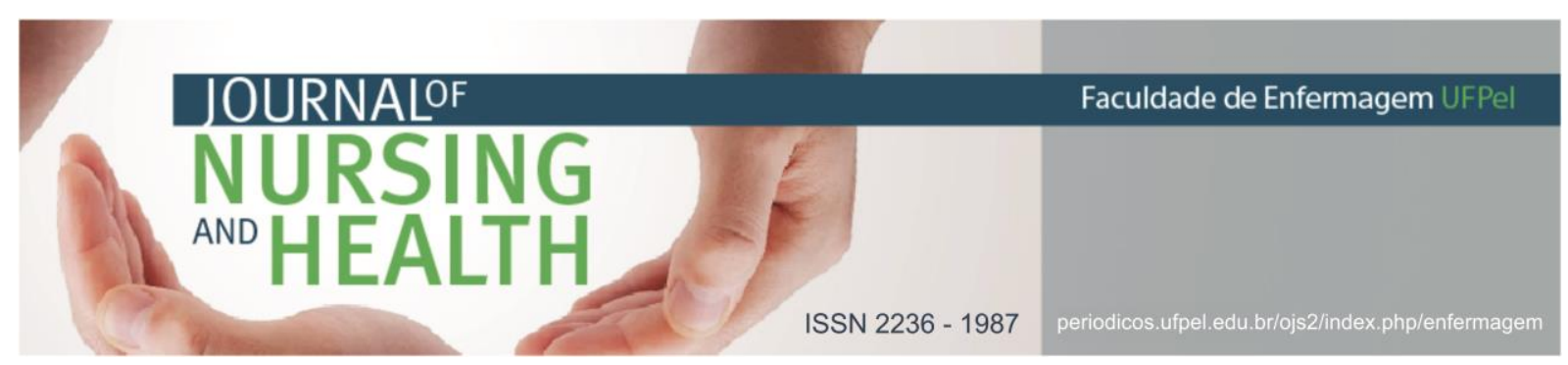

\section{Ron Coleman}

Em seu site pessoal ${ }^{1}$ Ron Coleman se apresenta como ativista no campo da saúde mental desde 1991, quando iniciou seu processo de recuperação. Desde então, ele tem escrito inúmeros artigos e livros sobre o assunto que é influente e colaborado com o desenvolvimento da rede de ouvidores de vozes no Reino Unido. Segundo o site, Ron trabalha com sua esposa Karen numa empresa denominada 'Working to Recovery' focada no trabalho para recuperação em saúde mental.

$\mathrm{Na}$ descrição de um jornal neozelandês ${ }^{2}$, o perfil que descreve Coleman, sob sua autorização, revela uma pessoa diagnosticada com esquizofrenia em 1982 que durante dez anos percorreu distintos manicômios britânicos, estando inclusive submetido por seis vezes a condição de paciente compulsório em secção 'selecionada'. Durante esta década, segundo os próprios relatos, Coleman esteve sujeito a diversos tratamentos que incluíram variados tipos, doses e combinações de medições psiquiátricas e a quarenta sessões de Eletroconvulsoterapia (ECT). Nascido em Dundee na Escócia, Coleman mudou sua vida quando em 1991 quando conheceu a rede de ouvidores de vozes que estava apenas se formando no Reino Unido. Atualmente, Ron Coleman vive muito feliz com sua família e sete vozes. Declarou ainda para o jornal que viaja o mundo tentando ajudar pessoas a conviverem com suas vozes, tendo em vista seus relatos de experiência.

$\mathrm{Na}$ apresentação de seu livro 'Working with voices II: Victm to Victor Workbook' ${ }^{3}$, segunda edição do livro 'Working with Voices l' que foi traduzido em quatorze idiomas, Ron se manifesta enquanto um ouvidor de vozes anunciando diferentes estratégias para o convívio com as vozes, sugerindo novos métodos de controle, e mais uma vez valorizando as experiências próprias do ouvidor. O livro sugere, desde seu título, a transformação e o empoderamento do ouvidor de vozes, uma vez que este deixa de ser a vítima e passa a ser o vitorioso sobre as vozes que escuta. Para Ron, o ouvidor de vozes é o centro do processo e é a sua experiência com a escuta de vozes que vai permitir o melhor convívio entre ouvidor e vozes.

Ron Coleman foi apresentado aos alunos da Faculdade de Enfermagem da Universidade Federal de Pelotas (UFPEL), aos trabalhadores e usuários dos serviços de saúde mental da região interessados e aos ouvidores de vozes presentes através de vídeos e artigos no Seminário de Enfermagem sobre Ouvidores de Vozes proposto pelo Programa de Pós-Graduação em Enfermagem da UFPEL durante o primeiro semestre de 2016. Durante o seminário, os participantes associaram Ron Coleman a possibilidade de convívio positivo com as vozes e ao êxito pessoal e profissional dos ouvidores de vozes, razões que justificavam o seminário.

Liderados por sua coordenadora, Luciane Prado Kantorski, proponente do seminário acima descrito, o Grupo de Pesquisa em Saúde Mental e Coletiva dedicase aos estudos sobre a temática dos ouvidores de vozes, dessa forma se fez presente no I Congresso Nacional de Ouvidores de Vozes. Nesta oportunidade, Ron Coleman em primeira aparição, apresentou-se ao público repetindo resumidamente sua biografia. Em seguida, em adequada oportunidade, posicionou-se de forma a deixar 


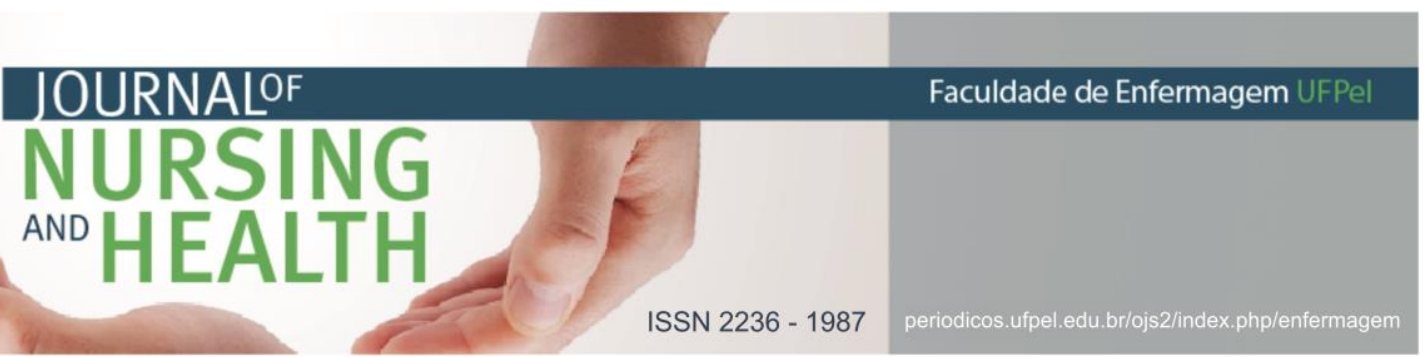

livre a visão de seu braço esquerdo, com a mão direita levantou a barra da manga da camisa que cobria o bíceps e mostrou a tatuagem onde lia-se 'esquizofrênico com orgulho’, esse era Ron segundo sua própria descrição.

\section{0 congresso}

Nos dias nos dias 20 e 21 outubro de 2017 o Brasil realizou o I Congresso Nacional de Ouvidores de Vozes, evento em que o Grupo de Saúde Mental e Coletiva da Faculdade de Enfermagem da Universidade Federal de Pelotas se fez presente. 0 congresso significou um marco histórico para os ouvidores de vozes brasileiros, bem como para os pesquisadores do assunto, uma vez que há mais de duas décadas os ouvidores de vozes têm se organizado por diversas outras partes do mundo.

O I Congresso Nacional de Vozes aconteceu nas instalações do Instituto de Psiquiatria da Universidade Federal do Rio de Janeiro (IPUB), foi organizado pelo IPUB e pelo Centro Educacional Novas Abordagens Terapêuticas (CENAT). O objetivo do Congresso era discutir a relevância do protagonismo do usuário em processos de reabilitação psicossocial e superação de crises. Tratava-se de um Congresso sobre a teoria e a prática dos ouvidores de vozes, com público preferencial composto por pessoas que vivem ou viveram, em primeira pessoa ou de forma muito próxima, os desafios do sofrimento psíquico e sua superação, buscando a experiência de compartilhamento do conhecimento que surge da experiência e toma a forma de práticas emancipadoras.

Ron Coleman foi palestrante do evento e esteve presente durante os dois dias de duração do encontro.

\section{A entrevista}

A narrativa que se segue no presente relato de experiência origina-se a partir de uma entrevista realizada a Paul Backer e Ron Coleman no dia 20 de outubro de 2017. O encontro com duração de uma hora e quarenta e cinco minutos, ocorreu ao entardecer, junto a área verde do IPUB, por ocasião término das atividades no primeiro dia do I Congresso Nacional de Ouvidores de Vozes. A entrevista fazia parte do projeto de sistematização das experiências deste congresso e foi proposto pela Faculdade de Enfermagem da Universidade Federal de Pelotas sendo coordenado pelo Grupo de Pesquisas em Saúde Mental e Coletiva desta mesma faculdade. Tendo como objetivo o relato das experiências pelos diversos atores presentes no congresso, a entrevista contava com duas perguntas orientadoras: qual a sua trajetória e qual sua relação com o movimento de ouvidores de vozes? Qual o seu envolvimento com o I Congresso Nacional de Ouvidores de vozes no Brasil e qual o significado deste evento sob seu ponto de vista? Um breve relato por parte dos entrevistados era esperado em resposta às questões propostas. 0 relato da entrevista de Paul Backer e Ron Coleman foi gravado em dispositivo apropriado e na sequência transcrito e traduzido pelas pesquisadoras responsáveis. O texto final, em formato de narrativa, compõe o próximo item deste documento. 


\section{NURSING \\ AND

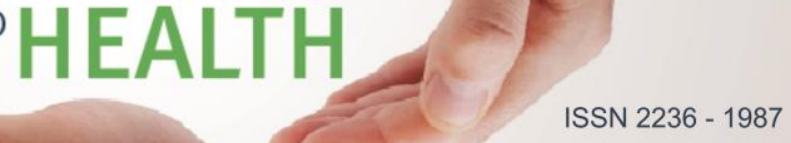

É importante relatar que embora a entrevista fosse dirigida a Paul Backer e Ron Coleman ambos os entrevistados ocuparam seus espaços individuais nas respostas o que permitiu as pesquisadoras observarem individualmente as narrações, assim apresenta-se em sequência a narrativa de Ron Coleman. Em relato de experiência paralelo localizado neste mesmo suplemento encontra-se disponibilizada a narrativa de Paul Backer.

A seguir, relatos sobre a trajetória e a relação com o movimento de ouvidores de vozes, contado por Ron Coleman.

\section{A trajetória com o movimento de ouvidores de vozes}

Eu não preciso de nada para entrar em contato com as minhas vozes, eu simplesmente, vou lá. Comigo funciona assim, quando chego em casa eu escuto as vozes, então quatro segundos se passam e eu entro em contato comigo, quero dizer que isso funciona um pouco, para mim, considerando que este seja o diálogo entre as vozes, já que é preciso negociar com cada voz.

Estou envolvido com o Movimento de Ouvidores de Vozes de vinte e quatro a vinte e cinco anos e para mim o meu papel no movimento sempre se relacionou com estabelecer e desenvolver.

Entender a experiência como própria e compartilhar um pouco mais de si mesmo está levando o Movimento de Ouvidores de Vozes de uma posição formal para uma posição informal. Não há mudança quando o relacionamento é apenas formal, na condição da informalidade as pessoas se sentem mais confortáveis, o que inclusive abre caminho para base profissional formal, como no exemplo a alucinação que permite ouvir vozes, ou ver coisas ou sentir cheiros.

No trabalho com as vozes não podemos permitir o eufemismo. As vozes podem ser de anjos ou diabos e se eu tentar trabalhar com o eufemismo nas suas vozes nós não conseguiremos bons resultados. Eu tenho que trabalhar com suas vozes como anjos, demônios e depois tentar criar elementos de segurança sobre isso. Existe também a estratégia de criar um espaço seguro entre a voz e o seu ouvidor, nesse sentido eu me coloco entre o ouvidor e a voz, peço que o ouvidor aponte o lugar de onde a voz surge e me coloco neste lugar de forma que possa olhar para o ouvidor, então digo: olhe para mim, eles não estão aqui!

Na nossa prática de trabalho com os ouvidores de vozes, nós consideramos sempre o Nós. Uma das mais importantes questões que respondo frequentemente é sobre porque eu decidi escrever e não os pacientes? Nós não sabemos o que os pacientes pensam, mas o que sabemos é como eles se descrevem, assim nós achamos mais fácil pedir aos ouvidores de vozes que descrevam suas próprias anotações e discutam-nas como uma conversa. Se por acaso discordamos fundamentalmente com o paciente, faremos uma anotação esclarecendo o ponto de discordância, mas é importante dizer que esta anotação não é dominante. 


\section{NURSING \\ AND

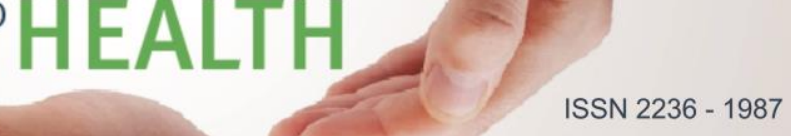

É preciso externalizar, se alguém está triste precisa simular esta tristeza e na forma como essa tristeza é simulada, encontramos muitas respostas. Nós, em nossa prática, tentamos coisas diferentes, sentamos na cadeira, usamos nossa mão, eu pergunto a um ouvidor de vozes: então me diga, como a voz se parece? $E$ eu sugiro que ele coloque a voz sob a sua mão e a observe, a maneira como ele segura a voz em sua mão e o modo como se comporta junto a cadeira onde está sentado podem realmente dizer mais sobre a voz descrita. Você ainda pode criar uma escultura da voz que escuta e colocar sob a sua mão, a escultura é uma oportunidade para a pessoa enxergar por si mesma o que está acontecendo. Na casa de recuperação da Austrália nós fazemos escultura todos os dias, isso faz parte da rotina. É preciso entender que se o meu trabalho é ajudar as pessoas em uma casa de recuperação, o trabalho delas é se recuperar, por isso que falo da rotina, a recuperação não existe em tempo parcial, a recuperação você faz em tempo integral por um período determinado.

Assumir, significa localizar a rua onde você mora, depois você precisa tornar essa rua uma comunidade de recuperação. Então você cria uma comunidade de recuperação e ao invés de algo que seja uma experiência da sociedade, você se torna experiente no seio da sociedade. $E$ assim que precisamos fazer a recuperação, no seio da sociedade, é realmente difícil colocar a recuperação fora do hospital, mas é assim que precisa ser. O hospital você precisa deixar lá, da forma como o conheceu e a recuperação precisa estar na sociedade, ela desconhece-se no hospital.

A recuperação é um desafio, e temos muito a oferecer frente a este desafio. Começa que o serviço sempre nos disse sobre os clientes, que nós teríamos os piores clientes, é nessa hora que todos pensam que nós falharemos. Acontece que a diferença destes clientes está no que eles escutam, já que nós dizemos alguma coisa que eles nunca ouvem. Nós perguntamos aos nossos clientes, $o$ que vocês desejam? E o que eles desejam não é nada mais do que alguém que escute suas vozes.

As pessoas não perceberam, mas eu lembro quando Marius Romme esteve surpreso, por compreender que uma das primeiras coisas que guiam os grupos de ouvidores de vozes é a criação de tempo e estrutura entre você e as vozes. A concretude do tempo com a estrutura de negociar com as vozes, o que na verdade é o próprio diálogo. É preciso encontrar a voz errada, tocar a parte inferior das vozes, é o jeito que você faz isso. A pessoa the diz eu ouço vozes que são externas, e então alguém repete: você ouve vozes, são internas, precisamos mover este caminho.

É a negociação com cada voz que possibilita que as vozes sejam barradas, com sinceridade, nós conseguimos encontrar uma ferramenta, uma coisa nova, que se chama diálogo com as vozes, e muitas pessoas não querem fazer, eu apenas olho e me pergunto, por quê? 


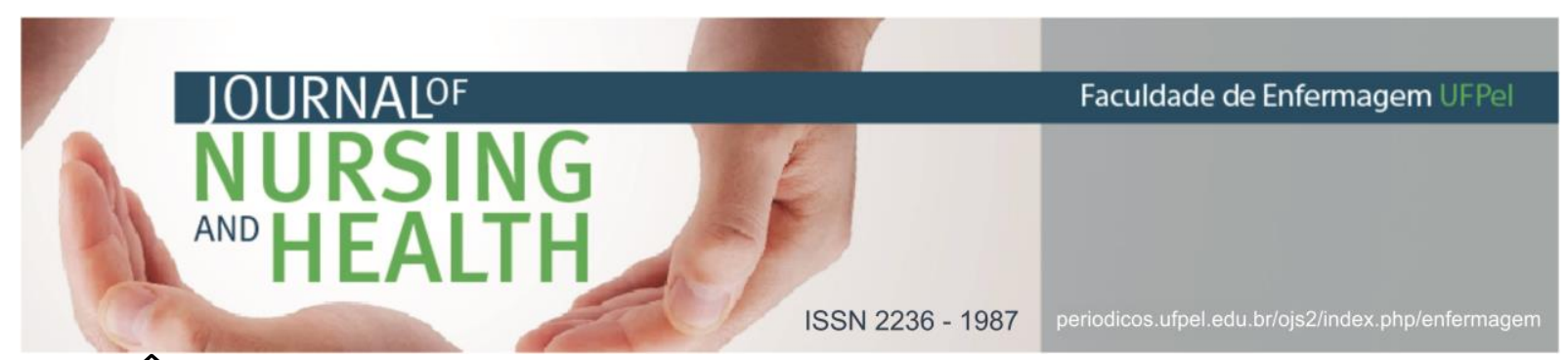

\section{REFERÊNCIAS}

1 Coleman R. Ron is one in a million. Working to Recovery Limited [Internet]. [cited 2018 Sept 10]. Available from: http: / / www.workingtorecovery.co.uk/roncoleman/here-and-now.aspx

2 New Zealand Herald. Conversations with ourselves [Internet]. 2011 June 03. [cited 2018 Mar 25]. Available from: http: / / www.nzherald.co.nz/nz/news/article.cfm?c_id=1\&objectid=10730081

3 Coleman, R, Smith, M. Working with Voices II: victim to Victor. $1^{\text {a }}$ ed. UK: Press LTD; 2005

4 Coleman, R, Smith, M. Working with Voices: victim to Victor. $1^{\text {a }}$ ed. Gloucester, UK: Handsell Publishing; 1997.

Data de publicação: 19/09/2018 